\title{
Prognostic Factors in Intracerebral Hemorrhage: A Hospital Based Prospective Study
}

\author{
Debabrata Goswami ${ }^{1}$, Tribeni Sharma ${ }^{2}$, Chandra Kr. Das ${ }^{3}$, Basabendra Choudhury ${ }^{4}$, Rajeev Bharadwaj ${ }^{3}$ \\ 1Professor \& HOD, ${ }^{2}$ Associate Professor, ${ }^{3 P G T}$, ${ }^{4}$ Registrar, \\ Department of Medicine, Gauhati Medical College, Guwahati, Assam, India.
}

\begin{abstract}
Introduction: Intracerebral hemorrhage (ICH), a form of stroke syndrome results from the rupture of an intracerebral vessel leading to the development of a hematoma in the substance of the brain. Incidence rates are particularly high in Asians and Blacks. Attempts are made to prognosticate $\mathrm{ICH}$ patients and manage them accordingly. This is particularly important for the socio-economic profile of the patients availing our services.

Methods: All together 90 patients of $\mathrm{ICH}$ were taken up in this study done in Gauhati Medical College and Hospital during the period from July 2013 to June 2015. Patients were diagnosed on the basis of a thorough medical history, a full neurological examination, standardized blood tests and CT scan of the brain. Prognostication was done on the basis of clinical and radiological findings. Prognosis was assessed as good or bad outcome on the 15th day based on neurological examination. Statistical analysis was done by using the chi-square test, fisher's t-test and student's t-test wherever applicable.

Results: In our study $35.55 \%$ patients showed bad outcome. Increasing age, low level of consciousness, low GCS score, bilateral limb weakness, high blood pressure, gaze palsies, pupillary abnormalities and CT brain findings of higher volume (>=30 ml) of hematoma, midline shift, intraventricular extension and a high ICH score were associated with bad outcome.
\end{abstract}

\section{INTRODUCTION}

Intracerebral hemorrhage $(\mathrm{ICH})$ which is a form of stroke syndrome results from the rupture of an intracerebral vessel leading to the development of a hematoma in the substance of the brain $^{1-3}$. Incidence rates are particularly high in Asians and blacks ${ }^{4}$. Intracerebral hemorrhage $(\mathrm{ICH})$ constitutes $10 \%$ to $15 \%$ of all strokes and has a higher risk of morbidity and mortality then cerebral infarction and subarachnoid hemorrhage (SAH) ${ }^{5}$. The 30 day mortality ranges between $30 \%$ to $40 \%$ in hospital based studies ${ }^{6,7}$.

Modifiable risk factors that increase the incidence of stroke include hypertension, smoking, alcohol, diabetes, dyslipidemia ${ }^{8-10}$ beside some non-modifiable risk factors ${ }^{11,12}$.

Attempts are being made to device optimal management strategies and to identify those who stand a poor prognosis with the available investigation and treatment options. This is particularly significant for the socio-economic profile of the patients availing our services.
Presence of comorbidities increased the likelihood of poor outcome. However, in our study lipid levels at presentation did not show any significant association with the outcome.

Conclusion: The intracerebral hemorrhage score (ICH score) can be considered as a simple and reliable clinical grading scale for predicting short term outcome in patients with spontaneous $\mathrm{ICH}$. However, lipid levels and blood sugar at presentation may not predict outcomes accurately.

Key Words: Intracerebral hemorrhage, Prognostic indicators, $\mathrm{ICH}$ score.

\section{*Correspondence to:}

Debabrata Goswami

Professor \& Head, Department of Medicine, Gauhati Medical College, Guwahati, Assam, India.

Article History:

Received: 04-08-2016, Revised: 07-08-2016, Accepted: 19-08-2016

\begin{tabular}{|l|c|}
\hline \multicolumn{2}{|c|}{ Access this article online } \\
\hline Website: & Quick Response code \\
www.ijmrp.com & \\
\hline DOI: & \\
10.21276/ijmrp.2016.2.5.007 & \\
\hline
\end{tabular}

Increasing age, low level of consciousness, low GCS score, abnormalities in arterial blood pressures, temperature, respiration at presentation, severity of weakness, speech disturbances, gaze palsies, brainstem involvement, higher volume of $\mathrm{ICH}$, infratentorial origin of $\mathrm{ICH}$, intra-ventricular or sub-arachnoid extension of $\mathrm{ICH}$, midline shift, higher $\mathrm{ICH}$ score have all been studied by various workers as important markers of bad prognosis after $\mathrm{ICH}^{5}$. Beside these, the presence of one or more co-morbid condition as well as some biochemical parameters at presentation has been found to influence outcome.

\section{AIMS \& OBJECTIVES}

1) To evaluate, compare and co-relate early clinical and CT scan findings in patients with intracerebral hemorrhage with outcome at 15 days in a hospital based prospective study.

2) To evaluate prognosis in relation to risk factors associated with intracerebral hemorrhage. 


\section{MATERIALS AND METHODS}

This was a hospital based prospective study conducted with 90 patients in the department of Medicine and Neurology, Gauhati Medical College and Hospital during the period from July 2013 to June 2015.

\section{Inclusion criteria}

Patients admitted with a history suggestive of hemorrhagic stroke of less than 7 day duration with a subsequent CT scan of the brain done at the earliest feasible hour confirming the diagnosis were taken up for the study with informed consent from the patient and/or the attendant. Only new cases are enrolled in the study.

\section{Exclusion Criteria}

Patients with hemorrhage secondary to brain tumors / to trauma or hemorrhagic transformation of cerebral infarct or aneurysmal or vascular malformation rupture or hematologic malignancies or subdural haematoma or cerebral amyloid angiopathy were excluded.

\section{Patient evaluation}

All patients were screened according to a strict protocol consisting of a complete medical history, a full neurological examination, standardized blood tests and a CT scan of the brain done at the earliest feasible period. The following data were prospectively collected: age, sex, recognized risk factors for spontaneous intracerebral hemorrhage (arterial hypertension, alcohol intake, smoking, diabetes mellitus, serum cholesterol levels, concomitant anticoagulant and antiplatelet treatment), glucose levels at admission, systolic, diastolic and mean blood pressure (defined as diastolic blood pressure plus $1 / 3$ [systolic - diastolic]), GCS scores (table 1), and CT scan findings. Neurological findings were determined from the initial CT scan and classified according to the site of $\mathrm{ICH}$ (basal ganglia, thalamic, lobar, pontine or cerebellar), volume of hematoma according to $A B C / 2$ method (explained later), midline shift (the displacement of the septum pellucidum across midline, using as reference a perpendicular line connecting the anterior and posterior insertions of the cerebral falx at the level of the lateral and third ventricle) and intra-ventricular extension of hemorrhage. In every patient intracerebral hemorrhage score ( $\mathrm{ICH}$ score) was calculated as devised by Hemphil et al $(2001)^{5}$ and its utility as a prognostic tool was evaluated.

Estimating the volume of the hematoma in the CT scan

The volume of the hematoma was calculated by using a simple and easily reproducible bedside method (Kothari, Brott, Broderick; $A B C$ 's of measuring intracerebral volume) ${ }^{13}$.

In this method, the CT slice with the largest area of hemorrhage was first identified. The largest diameter $(A)$ of the hemorrhage on this slice was measured. The largest diameter $90^{\circ}$ to $\mathrm{A}$ on the same slice was measured next (B). Finally, the approximate number of $10-\mathrm{mm}$ slices on which the $\mathrm{ICH}$ was seen was calculated (C). $\mathrm{C}$ was calculated by a comparison of each $\mathrm{CT}$ slice with the largest hemorrhage on that scan. If the hemorrhage area for a particular slice was greater than $75 \%$ of the area seen on the slice where the hemorrhage largest, the slice was considered 1 hemorrhage slice for determining $\mathrm{C}$. If the area was approximately $25 \%$ to $75 \%$ of the area, the slice was considered half a hemorrhage slice; and if the area was less than $25 \%$ of the largest hemorrhage, the slice was not considered a hemorrhage slice. These CT hemorrhage slice values were then added to determine the value for $C$. All measurements for $A$ and $B$ were made with the use of the centimeter scale on the CT scan to the nearest $0.5 \mathrm{~cm}$.
$A, B$, and $C$ were then multiplied and the product divided by 2 , which yielded the volume of hemorrhage in cubic centimeters.

Table 1: Showing calculation of ICH score: as devised by Hemphil et al (2001)

\begin{tabular}{lc}
\hline Clinical or Imaging Factor & Point Score \\
\hline Age & 0 \\
$<80$ years & 1 \\
80 years & \\
Hematoma Volume & 0 \\
$<30 \mathrm{cc}$ & 1 \\
$30 \mathrm{cc}$ & Present \\
Intraventricular Hemorrhage & 0 \\
No & 1 \\
YES & \\
Infratentorial Origin of Hemorrhage & 0 \\
No & 1 \\
YES & \\
Glasgow Coma Scale Score & 0 \\
$13-15$ & 1 \\
$5-12$ & 2 \\
$3-4$ & Sum of each \\
Total Score & category above \\
\hline
\end{tabular}

$\overline{\text { GCS score- indicates GCS score on initial presentation (or after }}$ resuscitation); $\mathrm{ICH}$ volume- volume on initial $\mathrm{CT}$ calculated using $\mathrm{ABC} / 2$ method; IVH - presence of any IVH on initial CT.

\section{Assessing prognosis}

All patients were followed up for 2 weeks during which vital signs were recorded and clinical improvement and deterioration was assessed. Follow up ceased with the death of the patient if it occurred within 2 weeks. Prognosis was assessed as good or bad outcome on the $15^{\text {th }}$ day. Patients who improved in neurological status from admission were grouped under good outcome whereas those who died or deteriorated from initial neurological status in the form of declining GCS score, increasing or new neurodeficits were grouped under bad outcome.

\section{Statistical Analysis}

Statistical analysis was done by using the chi-square test, fisher's t-test and student's t-test wherever applicable and these were performed using GraphPad InStat version 3.00 for Windows 7, GraphPad Software, San Diego California USA. All the statistical graphs were prepared using Microsoft Excel, 2007 and Microsoft Word 2007. Ethical committee clearance was taken from the IEC, Gauhati Medical College, Guwahati.

\section{RESULTS AND OBSERVATIONS}

90 patients of intracerebral hemorrhage $(\mathrm{ICH})$ admitted to the Department of Medicine and Neurology during the 1 year study period starting from July 2013 to June 2015 were evaluated in this study.

32 patients (35.55\%) ended up with bad outcome. $50 \%$ bad outcome was seen in 20-20 years age group. Overall $42 \%$ adverse outcome was noted in the patients of $\geq 60$ years of age. The mean age of cases with bad outcome was 58.32 years as compared to 54.89 years in patients with good outcome, the difference being statistically different $(<0.0001)$. The male: female ratio was $3.5: 1$. There was no statistically significant difference in outcome in relation of sex of patients. 
Worst outcome were noted in patients with convulsion (48.38\%), vomiting $(45.45 \%)$, hemiparesis $(37.6 \%)$, headache $(33.3 \%)$ and altered sensorium (30.2\%) in comparison to rest of all presenting features. 32 out of 78 cases with hypertension (41.05\%) showed bad outcome. Outcome was poor in diabetes $(58 \%) \&$ in patients with CKD $(66 \%)$ also. Patients with COAD showed the worst outcome $(80 \%)$. Patients who had two or more comorbid states had a relatively worse outcome.
Association of smoking and alcohol with ICH outcome

$50 \%$ patients i.e. 15 out of 30 in the smoker group and $48 \%$ i.e. 12 out of 25 in ethanolic group had unfavorable outcome. However the difference in outcome in relation to smoking ( $p$ value 0.073 ) and alcohol (0.199) was not statistically significant.

The alert and drowsy patients had better outcome compared with stuporous and comatose patients $(63.15 \%$ and $75 \%$ bad outcome respectively).

Table 2: Showing presenting features of patients with ICH

\begin{tabular}{lcccc}
\hline Complaints & $\begin{array}{c}\text { Total no. of } \\
\text { Cases }\end{array}$ & \%of total cases & $\begin{array}{c}\text { Total adverse } \\
\text { outcome }\end{array}$ & $\begin{array}{c}\text { \% of adverse } \\
\text { outcome }\end{array}$ \\
\hline Headache & 36 & 40.0 & 12 & 33.33 \\
Vomiting & 33 & 36.6 & 15 & 45.45 \\
Weakness & 85 & 94.44 & 32 & 37.64 \\
Altered Sensorium & 53 & 58.8 & 16 & 30.18 \\
Convulsion & 31 & 34.4 & 15 & 48.38 \\
Dizziness & 27 & 30.0 & 8 & 29.62 \\
Gait Unsteadiness & 28 & 31.1 & 8 & 28.57 \\
Confusion & 18 & 20.0 & 5 & 27.77 \\
Hemisensory & 20 & 22.2 & 4 & 20 \\
Symptoms & & & & 29.41 \\
Visual Disturbances & 17 & 18.8 & 5 & 2 \\
\hline
\end{tabular}

Table 3: Showing associated comorbidities and outcome

\begin{tabular}{lcccc}
\hline Comorbid state & No. Of cases & Good outcome & Bad outcome & $\begin{array}{c}\% \text { of bad } \\
\text { outcome }\end{array}$ \\
\hline Hypertension & $78(86.66 \%)$ & 46 & 32 & 41.05 \\
Diabetes Mellitus & $12(13.33 \%)$ & 5 & 7 & 58.33 \\
H/O stroke & $7(7.7 \%)$ & 5 & 2 & 28.51 \\
PVD & $4(4.44 \%)$ & 3 & 1 & 25 \\
COAD & $5(5.55 \%)$ & 1 & 4 & 80 \\
CKD & $9(10 \%)$ & 3 & 6 & 66.66 \\
IHD & $6(6.66 \%)$ & 4 & 2 & 33.33 \\
\hline
\end{tabular}

Table 4: Showing relation between level of consciousness at presentation and outcome

\begin{tabular}{lcccc}
\hline $\begin{array}{l}\text { Level of } \\
\text { Consciousness }\end{array}$ & Total & Good outcome & Bad outcome & \% Bad outcome \\
\hline Alert & & & 5 & 18.51 \\
Drowsy & $27(30 \%)$ & 22 & 9 & 25 \\
Stuporous & $36(40 \%)$ & 27 & 12 & 63.15 \\
Comatose & $19(21 \%)$ & 7 & 6 & 75 \\
\hline
\end{tabular}

Table 5: Showing relation between GCS score at presentation and outcome

\begin{tabular}{ccccc}
\hline GCS & No. of Patients & Good Outcome & Bad Outcome & \% Bad Outcome \\
\hline $3-5$ & $13(14.44)$ & 3 & 10 & 76 \\
$6-9$ & $24(26.67)$ & 12 & 12 & 50 \\
$10-12$ & $25(27.78)$ & 19 & 6 & 24 \\
$13-15$ & $28(31.11)$ & 24 & 4 & 14.28 \\
\hline
\end{tabular}

Around 53 (approximately 58\%) patients had a GCS>= 10 at presentation \& the outcome was relatively good in this group of patients $(81 \%)$. With GCS $<10$, the proportion of poor outcome increased significantly $(59.46 \%)$ with $p$-value of $<0.0001 .76 \%$ of patients with an initial GCS of 3-5 had a poor outcome. Statistically significant impact of systolic BP, pulse pressure \& mean arterial pressure at admission was seen on the bad outcome of the patients. Also patients presenting with an elevated temperature \& respiratory rate had a worse prognosis. The difference in pulse rate was not found statistically significant.

Thus both gaze palsies and pupillary abnormalities were associated with increased occurrence of bad outcomes. 
Table 6: Showing relation between vitals at presentation and outcome

\begin{tabular}{|c|c|c|c|c|}
\hline (Mean \pm SD) & Range & $\begin{array}{c}\text { Bad outcome } \\
(\text { Mean } \pm S D) n=32\end{array}$ & $\begin{array}{c}\text { Good outcome (Mean } \pm \\
\text { SD) } n=58\end{array}$ & $P$ value \\
\hline $\begin{array}{l}\text { Systolic BP } \\
(169.22 \pm 23.94)\end{array}$ & $126-230$ & $191.18 \pm 13.52$ & $157.10 \pm 19.38$ & $<0.0001$ \\
\hline $\begin{array}{l}\text { Diastolic BP } \\
(91.95 \pm 10.35)\end{array}$ & $70-112$ & $98.93 \pm 7.98$ & $88.10 \pm 9.50$ & $<0.0001$ \\
\hline $\begin{array}{l}\text { Mean BP } \\
(117.20 \pm 14.59)\end{array}$ & $89.33-150$ & $128.95 \pm 11.13$ & $110.76 \pm 12.03$ & $<0.0001$ \\
\hline $\begin{array}{l}\text { Pulse } \\
(71.07 \pm 13.89)\end{array}$ & $48-104$ & $69.75 \pm 14.63$ & $71.81 \pm 13.53$ & 0.5035 \\
\hline $\begin{array}{l}\left.\text { Temperature ( }{ }^{\circ} \mathrm{F}\right) \\
(98.2 \pm 0.96)\end{array}$ & $97-103$ & $98.85 \pm 1.18$ & $97.82 \pm 0.53$ & $<0.0001$ \\
\hline $\begin{array}{l}\text { Respiratory Rate } \\
(15.57 \pm 1.98)\end{array}$ & $12-21$ & $17.4 \pm 1.77$ & $14.56 \pm 1.24$ & $<0.0001$ \\
\hline
\end{tabular}

Table 7: Showing relation between Ocular posture and outcome

\begin{tabular}{lcccc}
\hline Ocular posture & Total cases & Good outcome & Bad outcome & \% bad outcome \\
\hline Normal orienting & $64(71.11)$ & 49 & 15 & 23.43 \\
Horizontal gaze palsy & $19(21.11)$ & 7 & 12 & 63.15 \\
Vertical gaze palsy & $7(7.77)$ & 2 & 5 & 71.42 \\
\hline
\end{tabular}

Table 8: Showing relation between Pupil size and outcome

\begin{tabular}{lcccc}
\hline Pupil size & Total cases & Good outcome & Bad outcome & \% bad outcome \\
\hline Normal & $76(84 \%)$ & 55 & 21 & 27.63 \\
Dilated & $9(10 \%)$ & 2 & 7 & 77.77 \\
Constricted & $5(5.55 \%)$ & 1 & 4 & 80 \\
\hline
\end{tabular}

Table 9: Showing degree of motor weakness and outcome

\begin{tabular}{lcccc}
\hline Weakness & Total No. of cases & Good outcome & Bad outcome & \% Bad outcome \\
\hline $\begin{array}{l}\text { Bilateral weakness } \\
\begin{array}{l}\text { Complete paralysis of one } \\
\text { side }\end{array}\end{array}$ & $5(5.55 \%)$ & 1 & 4 & 80 \\
$\begin{array}{l}\text { Unilateral variable } \\
\text { weakness }(\geq 3 / 5)\end{array}$ & $43(47.77 \%)$ & 17 & 20 & 54.05 \\
Normal Power & $5(5.55 \%)$ & 5 & 8 & 18.60 \\
\hline
\end{tabular}

Table 10: Showing side of motor weakness and outcome

\begin{tabular}{lccccc}
\hline Weakness & Total cases & Good outcome & Bad outcome & $\begin{array}{c}\text { \% of bad } \\
\text { outcome }\end{array}$ & P value \\
\hline Left & $39(43 \%)$ & 27 & 12 & 30.76 & 0.652 \\
Right & $49(54 \%)$ & 31 & 18 & 36.73 & \\
\hline
\end{tabular}

$80 \%$ adverse outcome was noted in the patients with bilateral motor weakness. Patients with complete one sided weakness had $54 \%$ unfavorable outcome. There was no statistically significant difference in outcome in relation to side of motor weakness in the patients of $\mathrm{ICH}$.

There was no significant difference in the outcome in relation to patient's initial random blood sugar level and fasting lipid profile including serum cholesterol, serum triglyceride, LDL and VLDL at presentation. Both patients of brainstem bleed died indicating $100 \%$ worst outcome. Other than that no significant difference in the outcome was noted with regard to different bleeding sites. $54.44 \%$ of the haemorrhages were left sided \& a relatively high proportion of patients $(40.81 \%)$ in this group had a poor outcome but the difference was not statistically significant.
38 patients had a haematoma volume of $\geq 30 \mathrm{ml}$. Significantly higher proportion ( $p$-value $<0.0001$ ) of poor outcome $(66.66 \%)$ was seen in this group as compared to those with haematoma size < $30 \mathrm{ml}$.

The mean midline shift was 0.55 with SD of 0.65 . Midline shift was associated with statistically significant mortality ( $p$-value < 0.0001)

One third of the patients in the study had ventricular extension of the bleed. $73.33 \%$ in this group of patients had a poor outcome compared to $16.66 \%$ among those without ventricular extension \& the difference was statistically significant.(p-value $<0.0001)$.

$20 \%$ of patients had ICH score 0 . None of them died whereas all patients with $\mathrm{ICH}$ score $\geq 4$ died. Poor outcome was seen with increasing $\mathrm{ICH}$ scores. 
Table 11: Investigations At Admission \& Outcome

\begin{tabular}{|c|c|c|c|c|}
\hline (Mean \pm SD) & Range & $\begin{array}{c}\text { Good outcome (Mean } \pm \text { SD) } \\
n=58\end{array}$ & $\begin{array}{l}\text { Bad outcome (Mean } \pm \\
\text { SD) } n=32\end{array}$ & $P$ value \\
\hline $\begin{array}{l}\text { RBS } \\
(118.77 \pm 33)\end{array}$ & $68-251$ & $115.24 \pm 33.55)$ & $125.18 \pm 33.55$ & 0.1819 \\
\hline $\begin{array}{l}\text { S. Cholesterol } \\
(188.01 \pm 44.29)\end{array}$ & $108-320$ & $183.21 \pm 43.19$ & $197.84 \pm 45.93$ & 0.1362 \\
\hline $\begin{array}{l}\text { HDL } \\
(51.78 \pm 10.99\end{array}$ & $29-71$ & $52.90 \pm 11.38$ & $49.75 \pm 10.10$ & 0.194 \\
\hline $\begin{array}{l}\text { Triglyceride } \\
(158.77 \pm 59.13)\end{array}$ & $55-352$ & $155.44 \pm 63.49$ & $164.81 \pm 50.67$ & 0.1225 \\
\hline $\begin{array}{l}\text { LDL } \\
(104.48 \pm 42.52)\end{array}$ & $17-248$ & $99.24 \pm 39.96$ & $113.97 \pm 45.94$ & 0.1162 \\
\hline $\begin{array}{l}\text { VLDL } \\
(431.75 \pm 11.83)\end{array}$ & $16-89$ & $31.06 \pm 12.68$ & $33 \pm 10.17$ & 0.4594 \\
\hline
\end{tabular}

CT SCAN FINDINGS

Table 12: Site of haematoma and outcome

\begin{tabular}{|c|c|c|c|c|c|c|}
\hline Site & $\begin{array}{c}\text { Total no of } \\
\text { cases }\end{array}$ & $\begin{array}{c}\% \text { of total } \\
\text { cases }\end{array}$ & Good outcome & Bad outcome & \multicolumn{2}{|c|}{$\%$ of bad outcome } \\
\hline Basal Ganglia & 46 & 51.11 & 28 & 18 & \multicolumn{2}{|r|}{39.15} \\
\hline Lobar & 15 & 16.6 & 10 & 5 & \multicolumn{2}{|r|}{33.33} \\
\hline Thalamus & 25 & 27.77 & 18 & 7 & \multicolumn{2}{|r|}{28} \\
\hline Cerebeller & 2 & 2.22 & 2 & 0 & & \\
\hline Brain Stem & 2 & 2.22 & 0 & 2 & \multicolumn{2}{|r|}{100} \\
\hline Side & $\begin{array}{c}\text { Total no of } \\
\text { cases }\end{array}$ & $\begin{array}{c}\% \text { of total } \\
\text { cases }\end{array}$ & $\begin{array}{c}\text { Good } \\
\text { outcome }\end{array}$ & Bad outcome & $\begin{array}{l}\% \text { of bad } \\
\text { outcome }\end{array}$ & $P$ value \\
\hline Left & 49 & 54.44 & 29 & 20 & 40.81 & 0.821 \\
\hline Right & 39 & 43.33 & 27 & 12 & 30.76 & \\
\hline
\end{tabular}

Table 14: Volume of haematoma and outcome

\begin{tabular}{lccccc}
\hline $\begin{array}{l}\text { Volume of } \\
\text { haematoma }(\mathrm{ml})\end{array}$ & Total & Good outcome & Bad outcome & \% bad outcome & P value \\
\hline$\geq 30$ & & & & & \\
\hline 30 & $38(42 \%)$ & 13 & 25 & 65.78 & $<0.0001$ \\
\hline
\end{tabular}

Table 15: Relation between midline shift and outcome

\begin{tabular}{lccccc}
\hline Midline shift $(\mathrm{mm})$ & Total & Good outcome & Bad outcome & \% bad outcome & P value \\
\hline$\geq 5$ & $27(30 \%)$ & 9 & 18 & 66.66 & $<0.0001$ \\
$<5$ or no shift & $63(70 \%)$ & 49 & 14 & 22.22 & \\
\hline
\end{tabular}

Table 16: Ventricular extension of the bleed and outcome

\begin{tabular}{lccccc}
\hline $\begin{array}{l}\text { Ventricular } \\
\text { extension of bleed }\end{array}$ & $\begin{array}{c}\text { Total no of } \\
\text { cases }\end{array}$ & Good outcome & Bad outcome & $\%$ of bad outcome & P value \\
\hline Present & $30(33 \%)$ & 8 & 22 & 73.33 & $<0.0001$ \\
Absent & $60(66 \%)$ & 50 & 10 & 16.66 & \\
\hline
\end{tabular}

Table 17: ICH score and outcome

\begin{tabular}{lccccc}
\hline ICH Score & No. of total patient & \%of total patient & Bad outcome & Good outcome & \% of bad Outcome \\
\hline $\mathbf{0}$ & 18 & 20 & 0 & 17 & 0 \\
$\mathbf{1}$ & 25 & 27.77 & 2 & 23 & 8 \\
$\mathbf{2}$ & 28 & 31.11 & 13 & 15 & 46.42 \\
$\mathbf{3}$ & 15 & 16.66 & 13 & 2 & 86.66 \\
$\mathbf{4}$ & 3 & 3.33 & 3 & 0 & 100 \\
$\mathbf{5}$ & 1 & 1.11 & 1 & 0 & 100 \\
$\mathbf{6}$ & 0 & 0 & 0 & 0 & \\
\hline
\end{tabular}




\section{DISCUSSION}

$\mathrm{ICH}$ is a medical emergency. Studies on prognostic factors in $\mathrm{ICH}$ patients are lacking in this part of the country. In this study we have analysed the prognostic factors which may help to predict the outcome of patients with $\mathrm{ICH}$.

Among 90 cases we studied, the incidence of intracerebral hemorrhage was found to have increased with advancing age. The mean age found in our study was $56.1 \pm 2.12$ years. Though most studies had found similar mean ages ${ }^{12,14,15}$, European studies have shown higher mean ages in the mid $7^{\text {th }}$ decades ${ }^{16}$. This discrepancy of age is probably due to lower life expectancy in the Indian population and predisposition to risk factors like diabetes, hypertension etc from a younger age. The difference in mean ages of patients with good and bad outcome was statistically significant $(p=<0.0001)$ and $42 \%$ bad outcome was noted in the patients of $\geq 60$ years of age. Most other workers ${ }^{16}$ support this data. The male: female ratio was 3.5: 1 though the outcome didn't vary significantly between the two sexes. Several other workers ${ }^{16-18}$ also support our observation.

Poor outcome in the patients with hypertension was found to be $41.05 \%$ similar to past studies. ${ }^{8}$ The outcome in diabetic patients was relatively poorer as compared to non-diabetic population ( $58 \%$ bad outcome for diabetic and $45 \%$ for non-diabetic). But the difference was not statistically significant. However, Ülkü Türk Börü et al.(2009) ${ }^{8}$ found high adverse outcome in diabetic population. This discrepancy might be due to small sample size in our study. $80 \%$ of patients with COAD had a bad outcome similar to some of the previous studies ${ }^{19}$. $33 \%$ of the patients were smokers and half of these patients had a bad outcome but statistically significant difference between the smokers and nonsmokers were not observed in terms of overall outcome ( $p$ value $=0.07$ ) as supported by some past studies ${ }^{20}$. The difference between the bad outcome in ethanolic patients and non-ethanolic was not statistically significant ( $p$ value $=0.199$ ), a finding similar to Helen Hansagi et al, $(1995)^{21}$. Not including the duration or amount or type or frequency of alcohol intake may be considered a drawback of this study.

In the present study we did not find any significant association between serum lipids at presentation and adverse outcome in our patients. However, Anuradha Bharosay et al (2013 $)^{22}$ found that low levels of serum cholesterol and serum triglycerides were associated with increased risks of hemorrhagic stroke and neurological worsening like some other workers. ${ }^{17,18,20}$ That cholesterol is known to have effects on the vasculature and is essential for normal membrane fluidity may be an explanation to the above findings ${ }^{23}$. Though earlier studies had showed an inverse relation between serum total cholesterol or high HDL level and hemorrhagic stroke $e^{922}$, Sugata Roy et a ${ }^{25}$ found no such association. Some previous studies found negative results whereas others found a positive association with high serum triglyceride concentrations and risk of stroke ${ }^{24}$. Also we did not find any association of serum blood glucose at the time of presentation with the immediate outcome as shown by other workers also ${ }^{14,26}$. This may be explained by the initial state of stress in such patients leading to high blood sugar levels. However, larger studies with multivariate logistic regression analysis need to be carried out to validate this.

There was poor outcome in the comatose and stuporous patients at admission. Statistically significant difference was noted in regards to outcome in patients with GCS above and below 10 $(p=<0.0001)$. Other studies also found increase in mortality with low level of consciousness and low GCS score at presentation. $8,16,23$

We got statistically significant association between blood pressure (both systolic, diastolic and mean arterial BP) of patients and outcome ( $p$ value $<0.0001$ ) which was similar to other studies ${ }^{27,28}$. High body temperature and respiratory rate of the patient at presentation showed an association with bad outcome which was statistically significant $(p=<0.0001)$ as found some of the past studies as well ${ }^{29}$.

The outcome in the group of patients with normal orienting eye movements was better $(76.6 \%)$ than those who had abnormalities of ocular posture. Both horizontal and vertical gaze palsies were associated with more bad outcomes. A study also reported that conjugate eye deviation (CED) was a significant predictor of death or dependency after acute supratentorial intracerebral hemorrhage even after adjusting for initial severity and hematoma volume ${ }^{30}$.

$78.57 \%$ bad outcome was found in the patients of $\mathrm{ICH}$ with abnormal pupil constricted/dilated) in the present study. A previous study also found $96 \%$ bad outcome with abnormal pupili31.

$5.5 \%$ patients had bilateral severe limb weakness, out of which $80 \%$ had bad outcome while patients with less severe limb weakness (power $\geq 3 / 5)$ the outcome was better $(82 \%$ good outcome). Other workers have also reported severe motor weakness as an predictor of early mortality $32-34$.

There was $100 \%$ mortality in the patients with brain stem bleed followed by $39.15 \%$ poor outcome with basal ganglia bleed, $33.33 \%$ in lobar and $28 \%$ with thalamic bleed in the present study. This finding was similar to past results. ${ }^{16}$

In the present study $42 \%$ patients had a hematoma volume $<30$ $\mathrm{ml}$ and $57 \%$ had $\geq 30 \mathrm{ml}$. $65 \%$ bad outcome was found in patients had $\geq 30 \mathrm{ml}$ whereas only $13 \%$ patients who had hematoma volume $<30 \mathrm{ml}$ fared badly. Statistically significant difference was noted in hematoma volume between good and poor responders ( $p$ value $<0.0001$ ) as was the result in previous studies as well12,15,35.

$30 \%$ patients had midline shift of $\geq 5 \mathrm{~mm}$ and the rest $70 \%$ had $<5 \mathrm{~mm}$ in there CT scan. $66 \%$ patients with a midline shift of $\geq$ $5 \mathrm{~mm}$ had a bad outcome while only $22 \%$ patients with a midline shift $<5 \mathrm{~mm}$ had bad outcome; the difference being statistically significant $(p=<0.0001)$. Various other workers also found increase in poor outcome with marked midline shift28,32.

In the present study, $66 \%$ patients with ventricular extension of the bleed in their CT scan had bad outcomes, while only $22 \%$ bad outcome was noted in the patients without ventricular bleed. The difference was statistically significant $(p=<0.00001)$ similar to several other studies 5,16 .

Bad outcome was associated with increase in ICH score. Various other studies also support this result5,14,36. The accuracy of this score in predicting outcome may be considered superior to admission GCS.

The intracerebral hemorrhage score (ICH score) thus can be considered as a simple and reliable clinical grading scale for predicting short term outcome in patients with spontaneous intracerebral hemorrhage. 


\section{CONCLUSION}

From the present study it can be concluded that proper assessment of different clinical parameters and findings on CT scan of brain can effectively prognosticate patients of spontaneous intracerebral hemorrhage with respect to short term morbidity and mortality. Clinical parameters that can predict outcome are state of consciousness at presentation, Glasgow coma scale score, systolic and diastolic blood pressure with mean arterial blood pressure, elevated body temperature and increased respiratory rate, vertical and horizontal gaze palsies, pupillary abnormalities and severity of motor weakness. Presence of comorbidities increased the likelihood of poor outcome.

$\mathrm{CT}$ findings including the $\mathrm{ICH}$ score can also accurately predict the outcome are - volume of hematoma $>30 \mathrm{ml}$, a midline shift of $\geq 5 \mathrm{~mm}$ and intraventricular extension of bleed.

However, lipid levels and blood sugar at presentation may not predict outcomes accurately.

Finally the $\mathrm{ICH}$ Score was found to be a better predictor of short term outcomes in patients with spontaneous intracerebral bleed.

\section{REFERENCES}

1. Aho K, Harmsen P, Hatano S, Marquardsen J, Smirnov VE, Strasser T. Cerebrovascular disease in the community: results of a WHO collaborative study. Bull World Health Organ. 1980; 58 : 113-130.

2. Ralph L. Sacco, Scott E. Kasner, Joseph P. Broderick, Louis R. Caplan. AHA/ASA Expert Consensus Document: An Updated Definition of Stroke for the 21st Century A Statement for Healthcare Professionals From the American Heart Association/American Stroke Association. Stroke $2013 \mathrm{Jul}$; 44(7):2064-89.

3. Kurtzke JF: Epidemiology of Cerebrovascular Disease. Berlin, Springer-Verlag, 1969;8-11.

4. Broderick J, Brott T, Tomsick T, et al: The risk of subarachnoid and intracerebral hemorrhages in blacks as compared with whites. N Engl J Med 326: 733, 1992.

5. Hemphill III JC, Bonovich DC, Besmertis L, Manley GT, Johnston SC. The ICH score - A sample, reliable grading scale for intracerebral hemorrhage. Stroke 2001;32:891-97.

6. Kwak R, Kadoya S, Suzuki T: Factors affecting the prognosis in thalamic hemorrhage. Stroke 14-4: 493-500, 1983.

7. Walshe TM, Davis KR, Fisher CM: Thalamic hemorrhage: A computed tomographic - clinical correlation. Neurology 27:217222, 1977

8. Lawes CM, Vander Hoorn S, Rodgers A. International Society of Hypertension. Global burden of blood pressure related disease, 2001. Lancet 2008; 371: 1513-8.

9. Xinguo Wang, Shaohua Li, Yongyi Bai, Xiaohan Fan, Kai Sun, Jizheng Wang, and Rutai Hui. Inverse association of plasma level of high-density lipoprotein cholesterol with intracerebral hemorrhage. The journal of lipid research, 2011 52:(9) 1747-1754. 10. Hayashi T., Kawashima S., Itoh H., Yamada N., Sone H., Watanabe H., Hattori Y., Ohrui T., Yokote K., Nomura H., et al. 2009. Low HDL cholesterol is associated with the risk of stroke in elderly diabetic individuals: changes in the risk for atherosclerotic diseases at various ages. Diabetes Care. 32: 1221-1223

11. Scarborough, $P$ Peto, V Bhatnagar, $P$, Kaur, A Leal J, LuengoFernandez R, Gray A, Rayner M, Allender S (2009) Stroke statistics. British Heart Foundation and Stroke Association: London. P44

12. Qureshi Al, Safdar K, WEli $\mathrm{J}$ et al. Predicor of early deterioration and mortality in black Americans with spontaneous intracerebral hemorrhage, Stroke 1995: 26:1764-7.

13. Kothari RU, Brott T, Broderick JP, et al: The ABCs of measuring intracerebral haemorrhage volumes. Stroke, 1996; 27:1304.

14. Rohit Bhatia, Hariom Singh, Shaily Singh, Madakasira V Padma, Kameshwar Prasad, Manjari Tripathi, Guresh Kumar, Mamta Bhushan Singh; A prospective study of in-hospital mortality and discharge outcome in spontaneous intracerebral hemorrhage; Neurology India, 2013; 61(3); 244-248.

15. Ji Woong Oh, M.D., Ji-Yong Lee, M.D.,2 Myeong Sub Lee, M.D., Hyen-Ho Jung, M.D., Kum Whang, M.D.; cliniThe Meaning of the Prognostic Factors in Ruptured Middle Cerebral Artery Aneurysm with Intracerebral Hemorrhage; J Korean Neurosurg Soc $52: 80-84,2012$.

16. Daniel Agustin Godoy, Gustavo Piñero, Mario Di Napoli; Predicting Mortality in Spontaneous Intracerebral Hemorrhage: Can Modification to Original Score Improve the Prediction? Stroke.2006:37:1038-1044.

17. Md Abu Naser Siddique, Zannatun Nur, Md Shahriar Mahbub, Md Billal Alam, Md Titu Miah; Clinical Presentation and Epidemiology of Stroke :A Study of 100 Cases,; Journal of Medicine, 2009;10:86-89

18. Azra Zafar, Farrukh Shohab Khan. Clinical and radiological features of intracerebral haemorrhage in hypertensive JPMA, July 2008; 58(7): 356-8.

19. Thie A, Spitzer K, Lappe h, Kunze K [Prognostic significance of clinical and instrumental parameters in spontaneous intracerebral hemorrhages [Journal Article] Fortschr neurol Psychiatr 1988May; 56(5):163-9.

20. Mansooreh Togha and Khadigeh Bakhtavar. Factors associated with in-hospital mortality following intracerebral hemorrhage: a three-years study in Tehran, Iran BMC Neurology 2004, 4:9.

21. Helen Hansagi, Anders Romelsjö, Maria Gerhardsson de Verdier, Sven Andréasson, Anders Leifman. Alcohol Consumption and Stroke Mortality. Stroke.1995; 26: 1768-1773.

22. Anuradha Bharosay, Vivek V. Bharosay, Debapriya Bandyopadhyay et al; Effect of Lipid Profile Upon Prognosis in Ischemic and Haemorrhagic Cerebrovascular Stroke. Indian J Clin Biochem. 2014 Jul; 29(3): 372-376.

23. Stein RW, Kase CS, Hier DB, et al Caudate hemorrhage. Neurology (NY) 1984; 34:1549.

24. Milionis HJ, Winder AF, Mikhailidis DP, Lipoprotein (a) and stroke. Journal Clin Pathol 2000; 53:487-96.

25. Sugata Roy Chaudhury, Siddhartha Ghosh and Debdatta Kar; Comparative lipid profile study between ischemic and hemorrhagic stroke. Journal of Chemical and Pharmaceutical Research, 2014, 6(11):20-27.

26. Sunil K. Narayan, P. Sivaprasad, Sharma Sushma, Ratnakar K. Sahoo, and Tarun Kumar Dutta, Annals of Indian Academy of Neurology- 2012 Oct-Dec; Etiology and outcome determinants of intracerebral hemorrhage in a south Indian population, A hospitalbased study. Ann Indian Acad Neurol. 2012 Oct-Dec; 15(4): 263266. 
27. Fogelholm R, Avikainen S, Murros K. Prognostic value and determinats of first-day mean arterial pressure in spontaneous supratentorial intracerebral hemorrhage. Stroke 1997; 28:1396400.

28. Lars Sjöblom, Hans-Göran Hårdemark, Arne Lindgren, Bo Norrving, Martin Fahlén, Margareta Samuelsson, Lennart Stigendal, Dick Stockelberg, Ali Taghavi, Lena Wallrup and Jonas Wallvik; Management and Prognostic Features of Intracerebral Hemorrhage During Anticoagulant Therapy: A Swedish Multicenter Study; Stroke, 2001; 32: 2567-2574.

29. Deogaonkar A, Georgia MD, Bae C, Abou-Chebl A, Andrefsky J. Fever is associated with third ventricular shift after intracerebral hemorrhage: Pathophysiologic implications. Neurol India 2005; 53:202-7.

30. Sato S, Koga M, Yamagami $\mathrm{H}$ et al; Conjugate eye deviation in acute intracerebral hemorrhage: stroke acute management with urgent risk-factor assessment and improvement--ICH (SAMURAIICH) study. Stroke. 2012 Nov; 43(11):2898-903.

31. Portenoy RK, Lipton RB, Berger AR et al: Intracerebral hemorrhage: A model for the prediction of outcome. J Neurol Neurosurg. Psychiatry 50:976, 1987.

32. Mase G, Zorzon M, Biasutti E, et al. Immediate prognosis of primary intracerebral hemorrhage using an easy model for the prediction of survival. Acta Neurol Scand 1995; 91:306-9

33. Hallevy $C$, ifergane $G$, Kordsh $E$, et al. Spontaneous supratentorial intracerebral hemorrhage. Criteria for short-term functional outcome prediction. J Neurol 2002; 249:1704-9
34. Tuhrim S, Dambrosia JM, Price TR, et al Prediction of intracerebral hemorrhage survival. Ann neurol 24: 258,1988.

35. Dzevdet Smajlović, Denisa Salihović, Omer C Ibrahimagić, Osman Sinanović; Characteristics of stroke in young adults in Tuzla Canton, Bosnia and Herzegovina; University of Tuzla, Tuzla University Clinical Centre, Medical Faculty, Department of Neurology, 2005, Coll. Antropol. 37 (2013) 2: 515-519.

36. Jennifer L. Clarke, S. Claiborne Johnston,1 Mary Farrant, Richard Bernstein, David Tong, and J. Claude Hemphill III External Validation of the ICH Score, Neurocritical care, 2004;1: 53.

\section{Source of Support: Nil. Conflict of Interest: None Declared. \\ Copyright: () the author(s) and publisher. IJMRP is an official publication of Ibn Sina Academy of Medieval Medicine \& Sciences, registered in 2001 under Indian Trusts Act, 1882. \\ This is an open access article distributed under the terms of the Creative Commons Attribution Non-commercial License, which permits unrestricted non-commercial use, distribution, and reproduction in any medium, provided the original work is properly cited.}

Cite this article as: Debabrata Goswami, Tribeni Sharma, Chandra Kr. Das, Basabendra Choudhury, Rajeev Bharadwaj. Prognostic Factors in Intracerebral Hemorrhage: A Hospital Based Prospective Study. Int J Med Res Prof. 2016; 2(5):32-39. 